\title{
The Coordination Decision of Dual-Channel Fresh Food Supply Chain
}

\author{
Nie Qixuan*, Xie Fengqin, Yu Hongfei \\ College of Transportation, Shandong University of Science and Technology, Qingdao, China \\ Email address: \\ 609362504@qq.com (Nie Qixuan), chilias22@163.com (Xie Fengqin), yuhongfeiqing@qq.com (Yu Hongfei) \\ ${ }^{*}$ Corresponding author
}

\section{To cite this article:}

Nie Qixuan, Xie Fengqin, Yu Hongfei. The Coordination Decision of Dual-Channel Fresh Food Supply Chain. International Journal of Intelligent Information Systems. Vol. 8, No. 1, 2019, pp. 6-11. doi: 10.11648/j.ijiis.20190801.12

Received: January 7, 2019; Accepted: February 25, 2019; Published: March 20, 2019

\begin{abstract}
More and more suppliers in fresh food supply chain expand online channels using fresh food e-commerce platform, forming a dual-channel supply chain model. The competition of market resources will lead to channel conflict in the dual-channel fresh food supply chain. The level of service is one of the important reasons for the conflict in the fresh food supply chain. Service is an important factor influencing the shopping decision of consumers. This paper studies a dual-channel supply chain consisting of a fresh food supplier and a fresh food retailer. The supplier wholesale fresh food to the retailer while developing its own online channel. In this paper, the Stackelberg game model is used to solve the equilibrium state of service level between the supplier and the retailer in the dual-channel supply chain. Both the supplier and the retailer aim to maximize profits. The supplier is the game leader. It first decides the wholesale price and the service level of the online channel. The retailer is the follower. It makes decisions based on the supplier's decisions. The study found that the supplier and the retailer can attract more customers by improving service level, thus increasing profits. Weighing the relationship between service level and operation cost is a major problem in operation.
\end{abstract}

Keywords: Dual-channel Supply Chain, Stackelberg Game, Service Level

\section{Introduction}

With the continuous upgrading of information technology, e-commerce not only brings challenges to the traditional retail industry, but also brings this trend to the upstream of the supply chain. More and more suppliers are beginning to expand their sales channels to strive for a larger market share. The booming fresh food industry is also gradually separated from a single traditional business model, and numerous fresh food e-commerce platforms of various forms have emerged. Many fresh food supply chain suppliers have opened online sales channels through such fresh food e-commerce platform, forming an online and offline double-channel supply chain model. In the dual-channel supply chain of fresh food, channel conflict is always caused by the competition of market resources. A number of studies analyzed the case of an independent physical store retailer facing new competition from the direct e-channel of a manufacturer [1-3]. Khouja et al. [4] indicated that the most critical factor in channel selection in a vertically integrated supply chain is the variable cost per unit of product sold using the direct vs. the retail channels. Xu et al. [5] present an analytical framework for price decisions in a centralized and a decentralized dual-channel supply chain with risk-averse and proposed a coordination scheme for a dual-channel supply chain. Cai [6] analyzed the impact of a price discount contract and pricing scheme on the dual-channel supply chain and reported that the simple price discount contract can improve the performance of both the supplier and the retailer. Most of the literature on the dual-channel supply chain is mainly focused on optimizing the profit of a supply chain when both the manufacturer and the retailer offer a single product (standard) through the dual-channel [7-11]. ZHENG et al. [12] present a strategic analysis of manufacturer-retailer interaction in a dual channel setting and an analytical model that incorporates the key trade-offs regarding the channels. Dan's research [13] revealed that the ratio of demand relative increase and the degree of customer loyalty to the retail channel have great effects on the retail services and pricing decisions. Lu et al. 
[14] found that channel acceptance plays a critical role in influencing equilibrium prices and profits in the dual-channel distribution system. Soleimani et al. [15] suggested that production cost and demand disruptions are highly correlated, and they influence the pricing and production decisions. Therefore, both disruptions should be considered simultaneously.

Service level is one of the important reasons for the conflict of fresh food supply chain. Service is an important factor influencing shopping decision of consumers. For fresh products, offline sales channels can provide customers with services such as selection and preliminary treatment of fresh products. Online channels include automated and manual customer service for answering questions, as well as fresh food delivery services. Suppliers and retailers can attract more customers and increase sales by improving service level. However, the improvement of service level also means the increase of cost. How to balance the relationship between service level and operation cost becomes a major problem. Since the same products are sold, suppliers and retailers compete for consumers in the potential fresh product market through the improvement of service level.

\section{The Model}

The Stackelberg game model is a kind of decision making problem with master-slave relation among game players. The players each control a portion of the decision variables to optimize their goals. The upper decision-maker has greater power; the lower decision-maker is in a passive position. But lower decision-maker also has some autonomy. The result of its decision will affect the decision of the upper decision-maker.

The process of the Stackelberg game is: The upper decision-maker makes decisions according to its own decision-making objectives. The lower decision-maker makes choices based on decisions made by upper decision maker. When selecting strategies, the upper decision-maker will consider the strategies that the lower ones may adopt and the influence on it. Therefore, the final decision of each decision maker should be acceptable and satisfactory.

In this paper, the following parameters are set up to establish the game model of fresh food dual-channel in service level:

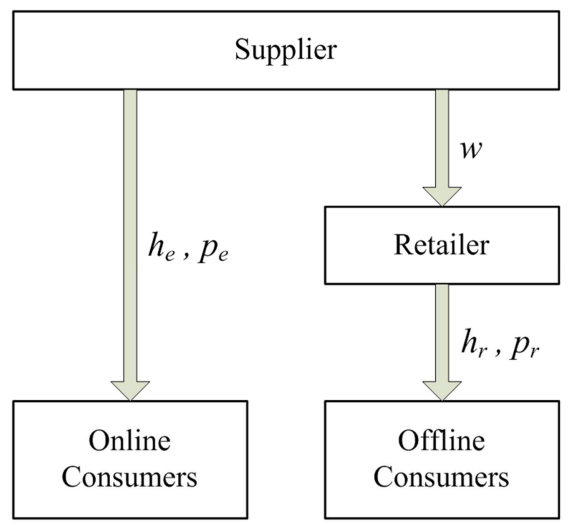

Figure 1. Sales process.
Table 1. List of notations.

\begin{tabular}{ll}
\hline \multicolumn{2}{l}{ List of notations } \\
\hline$p_{e}$ & the online price of fresh food \\
$p_{r}$ & the offline price of fresh food \\
$w$ & the wholesale price of fresh food \\
$c_{m}$ & the unit cost of supplier \\
$c_{r}$ & the unit cost of retailer \\
$A$ & the potential demand of the whole market \\
$\lambda$ & the proportion of online demand in the total market demand \\
$\mu$ & the sensitivity of demand to price \\
$h_{e}$ & service level of the online channel \\
$h_{r}$ & service level of the offline channel \\
$\alpha_{1}$ & the sensitivity of online channel consumers to the service level \\
$\alpha_{2}$ & the sensitivity of offline channel consumers to the service level \\
$\beta$ & crossed service elasticity coefficient between channels \\
$\eta$ & service cost factor \\
$D_{e}$ & the actual demand of fresh food in online channel \\
$D_{r}$ & the actual demand of fresh food in offline channel \\
$\pi_{m}$ & supplier's profit \\
$\pi_{r}$ & retailer's profit \\
\hline
\end{tabular}

In the sales process, the supplier and the retailer make service level decisions according to their own interests. This part use Stackelberg game theory to solve the problem. The supplier is the core enterprise of supply chain and the dominant player of game. The retailers is the follower. First, the supplier set the wholesale price for the retailer and online channel service level. Next, the retailer decide the service level of the offline channel according to the decisions of the suppliers and its own market conditions. The supplier then adjusts the wholesale price and online channel service level according to the service level of the retailer. Through continuous game, the players reach equilibrium. In this game model, the profits of suppliers and retailers are as follows:

$$
\begin{gathered}
\pi_{m}=\left(p_{e}-\eta h_{e}-c_{m}\right) D_{e}+w D_{r} \\
\pi_{r}=\left(p_{r}-w-\eta h_{r}-c_{r}\right) D_{r}
\end{gathered}
$$

The solution is solved by backward induction. Firstly, analyze the response function of the retailer after the supplier sets the wholesale price and online channel service level. The retailer's response function is

$$
h_{r}\left(w, h_{e}\right)=\frac{-\eta(1-\lambda) A+\mu \eta p_{r}+\beta \eta h_{e}-\left(w+c_{r}+p_{r}\right) \alpha_{2}}{2 \alpha_{2} \eta}
$$

Then the retailer's response function is then substituted into the supplier's profit expression. Obtain the equilibrium solution of supplier's wholesale price and online service level:

$$
\begin{aligned}
& w^{*}=\frac{\beta \mu \eta p_{e}+\left(\beta^{2}-\alpha_{1} \alpha_{2}+\alpha_{1} \mu \eta\right) p_{r}-\left[(1-\lambda) \alpha_{1}+\beta \lambda\right] \eta A}{2\left(\beta^{2}-\alpha_{1} \alpha_{2}\right)}-\frac{1}{2} c_{r} \\
& h_{e}^{*}=\frac{-\beta \mu \eta p_{r}+\left(\beta^{2}-\alpha_{1} \alpha_{2}-\alpha_{2} \mu \eta\right) p_{e}-\left[(1-\lambda) \beta+\alpha_{2} \lambda\right] \eta A}{2 \eta\left(\beta^{2}-\alpha_{1} \alpha_{2}\right)}-\frac{1}{2 \mu} c_{m}
\end{aligned}
$$

Finally, the equilibrium wholesale price is substituted into the retailer's response function to obtain the retailer's equilibrium service level. Because the expression is too 
complicated, the next section presents the results more visually using numerical analysis.

\section{Numerical Simulation Analysis}

In this section, the service level decision model of the dual-channel fresh food supply chain is simulated numerically. The parameter values are set as follows:
Table 2. Values of the parameters.

\begin{tabular}{lllllllllll}
\hline$\lambda$ & $\boldsymbol{p}_{\boldsymbol{e}}$ & $\boldsymbol{p}_{\boldsymbol{r}}$ & $\boldsymbol{c}_{\boldsymbol{m}}$ & $\boldsymbol{c}_{\boldsymbol{r}}$ & $\boldsymbol{\alpha}_{\boldsymbol{1}}$ & $\boldsymbol{\alpha}_{\boldsymbol{2}}$ & $\boldsymbol{\beta}$ & $\boldsymbol{\eta}$ & $\boldsymbol{A}$ & $\boldsymbol{\mu}$ \\
\hline 0.5 & 30 & 25 & 6 & 5 & 2 & 3 & 1 & 0.7 & 100 & 2 \\
\hline
\end{tabular}

The following (Figure 2-6) shows the influence of parameter changes on the supplier's and the retailer's service level decision making.

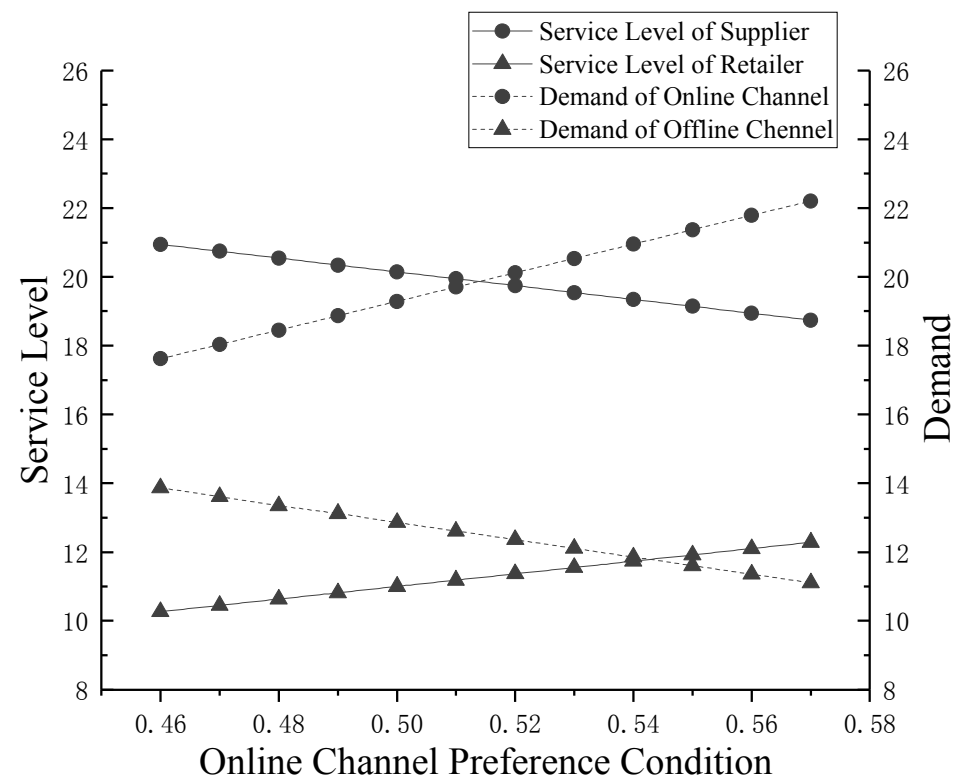

Figure 2. Service level and demand in different online channel preference condition.

As the preference of the online channel increases, the service level of the online channel decreases, but the sales volume increases. This shows that, relying on the trust of consumers, the suppliers ignores the improvement of service level. But in real life, such enterprises will not last long. As $\lambda$ rises, the retail sales fall and the service levels rise. It shows that when consumers turn to online channels to buy fresh food, the retailer will strive to improve the service quality of the offline channel and win more attention from consumers. This is consistent with the reality. As $\lambda$ rises, wholesale prices fall. Because there's less demand for them. So the supplier have to lower the wholesale price to stimulate the retailer to order.

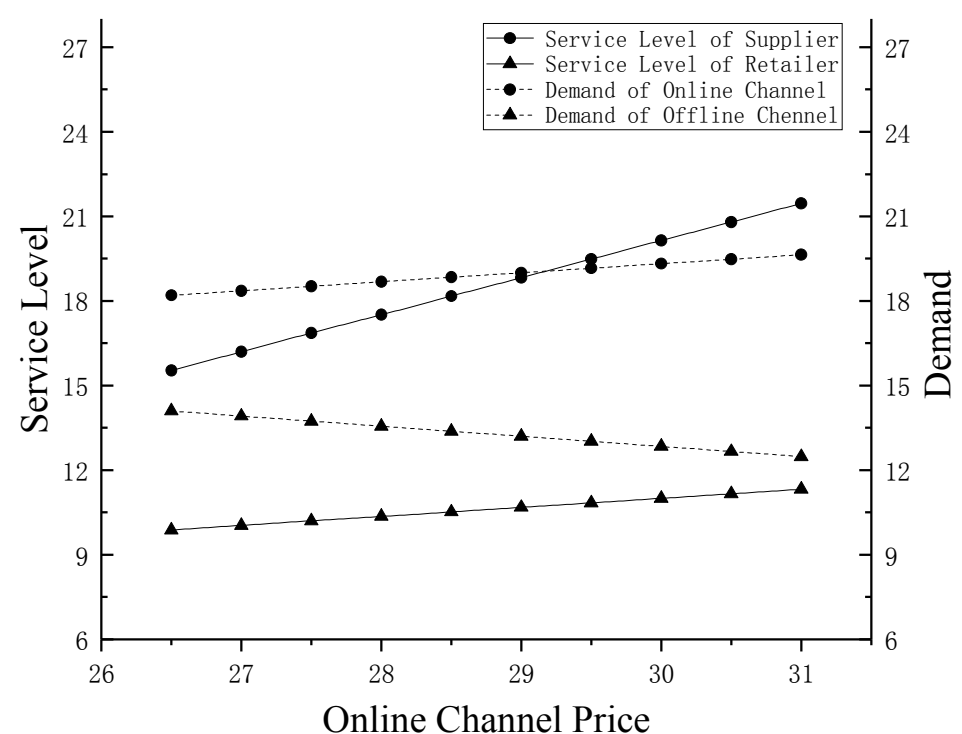

Figure 3. Service level and demand in different online channel price.

With the increase of online channel prices, both the service level and the sales volume of the supplier increase, while the service level of the retailer increases but its sales volume decreases. That's because at this point $\alpha_{1}-\mu \eta=0.6>0$. When 
the cost of service is fixed, the service level of online channel is more sensitive to demand. At this point, the increase of online channel service level to the demand is greater than the decrease of price to the demand. The comprehensive performance is the increase in demand for the online channel. The increasing demand of the online channel is bound to lead to the decrease of the demand of the offline channel. The retailer will try to improve service and win back consumers. Therefore, when the service level of the online channel is more sensitive to demand, appropriately increasing the price of the online channel can improve the service level of the two channels. At the same time, we have noticed that wholesale prices decrease with the increase in $p_{e}$. As demand from the retailer drops, the supplier need to lower wholesale price to keep the retailer ordering more The supplier's profit includes the income from wholesaling goods to the retailer. This decrease in revenue will result in a decrease in the overall profit of the supplier.

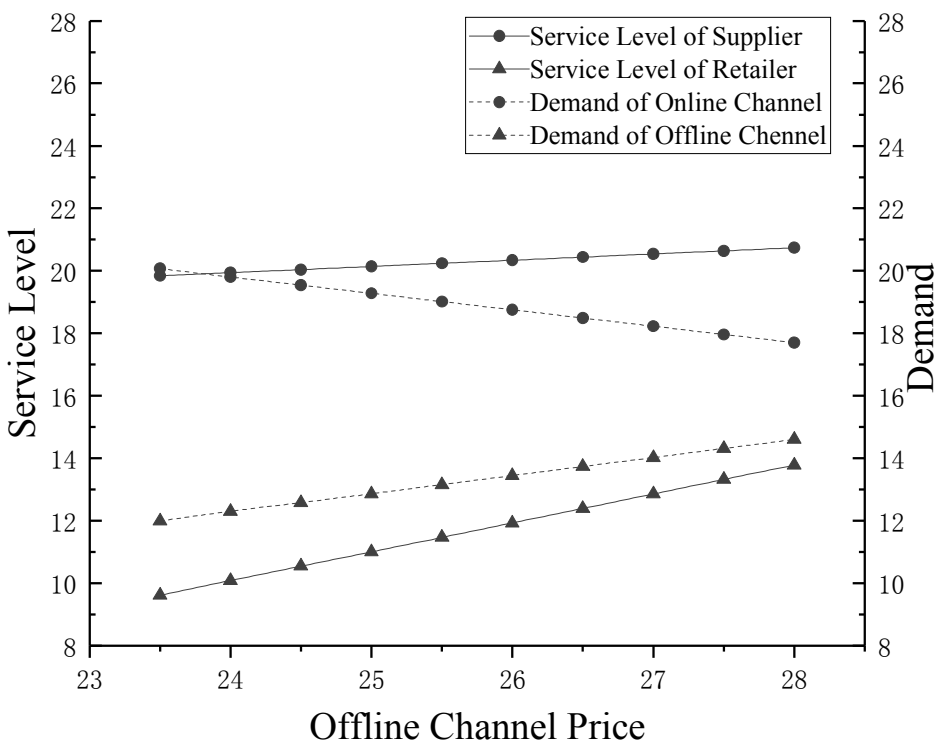

Figure 4. Service level and demand in different offline channel price.

With the increase of offline channel price, the service level of the supplier increases but the sales volume decreases, while the service level and sales volume of the retailer both rise. Because $\alpha_{2}-\mu \eta=1.6>0$, when the cost of service is fixed, the service level of the offline channel is more sensitive to demand. At this point, the increase in demand for offline channel service level is greater than the decrease in demand for price. The comprehensive performance is that the demand for the offline channel increases. And the increase of the demand of offline channel is bound to bring about the decrease of the demand of online channel. The suppliers will try to improve their services to attract consumers. At the same time, wholesale prices rose with the increase in $p_{r}$. As demand from the retailer rises, the supplier raise wholesale prices to make more profit. This could also explain the decline in retailers' overall profits. The retailer's wholesale cost increases, resulting in an increase in total cost and a decrease in the retailer's overall profit.

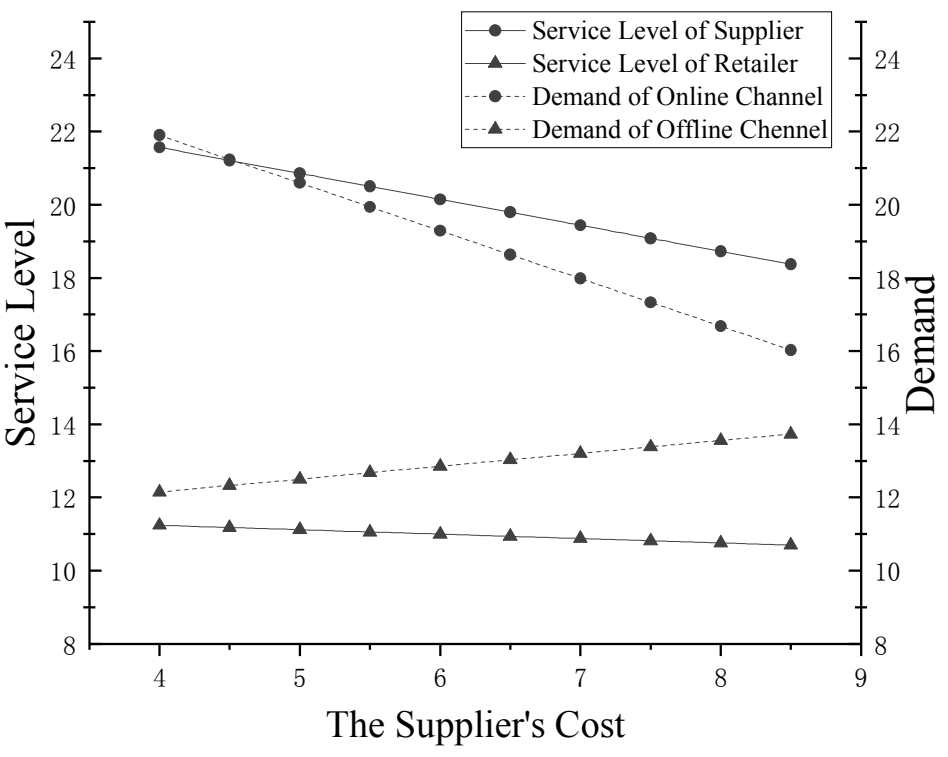

Figure 5. Service level and demand in different supplier's cost. 
As $c_{m}$ rise, the supplier's service level and sales volume fall. The retailer's service level remained unchanged or declined slightly, and the sales volume increased. The cost of the supplier makes the online channel owned less competitive. So there is less demand for the online channel. Demand shifts to the retailer, boosting its profit. When the cost is low, the degree of profit increase of the retailer is greater than the degree of profit loss of the supplier, resulting in the increase of

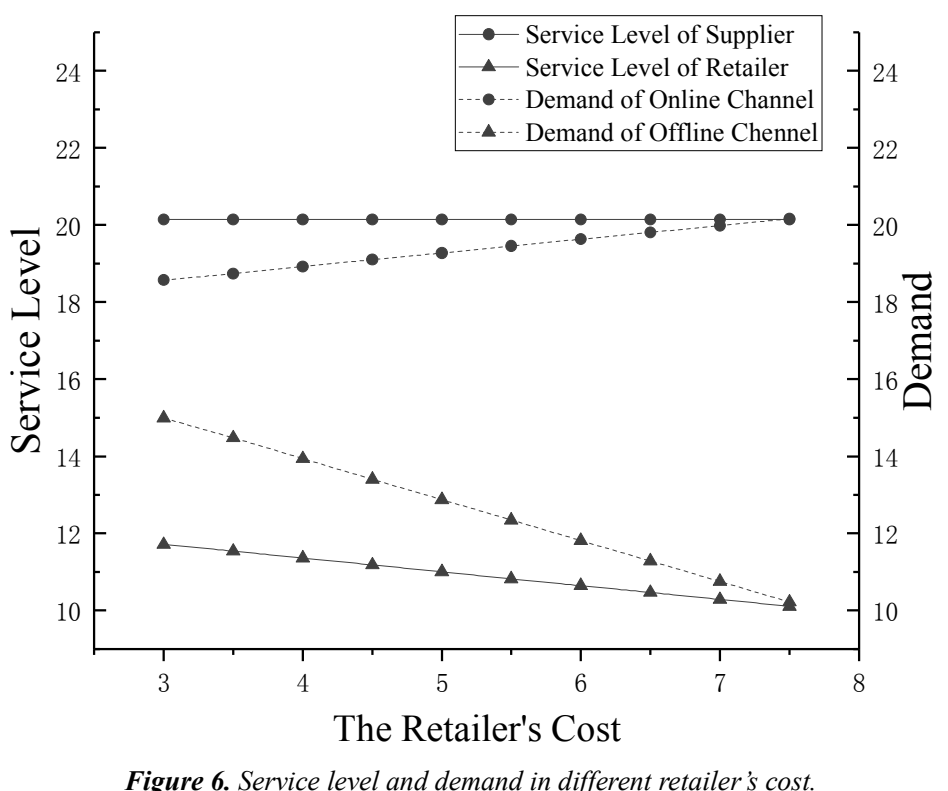

Figure 6. Service level and demand in different retailer's cost.
When the retailer's cost increases, the service level of the supplier remained stable or slightly increased, and the demand increased. But the retailer's service level and demand have fallen. The reason is that the rising cost weakens the competitiveness of the retailer's offline channel, resulting in the decline of service level. At the same time, the service level of the supplier is relatively improved, and the demand is rising, which brings an increase in profits. But to stimulate the retailer to order, the supplier must lower the wholesale price. This results in a loss of profit. When the profit loss caused by the decrease of wholesale price is greater than the profit increase caused by the increase of sales volume, the overall profit of the supplier presents a downward trend.

\section{Conclusion}

Fresh food dual-channel supply chain includes online channels and traditional offline sale channels. The online channel belongs to the supplier, and the offline channel belongs to the retailer. They all want to make the best decision in order to maximize their profits. By improving service levels, the supplier and the retailer can attract more customers. For example, when customers prefer the online channel, the retailer's sales will decline. Then the retailer will try to improve the service level of the offline channel to win more attention from consumers. In the fresh food industry, service level is an important factor affecting consumers' choice. In the process of sales, the suppliers and the retailer constantly overall profit. When the cost is high, the increase of the retailer's profit is not enough to make up for the loss of the supplier's profit, resulting in the decrease of overall profit. The rising cost weakens the online channel competitiveness of the supplier and leads to the decline of service level. That led to a drop in sales volume. On the other hand, the retailer's relative service level has improved and the demand has increased, which brings a huge increase in profits. compete with each other in terms of service level and price. And through the improvement of service level to compete with consumers in the potential market of fresh food.

\section{References}

[1] Liu Y, Zhang Z J. Research Note---The Benefits of Personalized Pricing in a Channel [J]. Marketing Science, 2006, 25 (1): 97-105.

[2] Liang xi, Huang chengfeng, Xie shuiqing. Influence of direct selling cost on sales channel decision in dual-channel supply chain [J]. Industrial engineering, 2010 (4).

[3] Lu Q, Liu N. Effects of e-commerce channel entry in a two-echelon supply chain: A comparative analysis of singleand dual-channel distribution systems [J]. International Journal of Production Economics, 2015, 165: 100-111.

[4] Khouja M, Park S, Cai G. Channel selection and pricing in the presence of retail-captive consumers [J]. International Journal of Production Economics, 2010, 125 (1): 84-95.

[5] Xu G, Dan B, Zhang X, et al. Coordinating a dual-channel supply chain with risk-averse under a two-way revenue sharing contract $[\mathrm{J}]$. International Journal of Production Economics, 2014, 147 (1): 171-179.

[6] Cai G, Zhang Z G, Zhang M. Game theoretical perspectives on dual-channel supply chain competition with price discounts and pricing schemes $[\mathrm{J}]$. International Journal of Production Economics, 2009, 117 (1): 80-96. 
[7] Yue X, Liu J. Demand forecast sharing in a dual-channel supply chain [J]. European Journal of Operational Research, 2006, 174 (1): 646-667.

[8] Hua G, Wang S, Cheng T C E. Price and lead time decisions in dual-channel supply chains [J]. European Journal of Operational Research, 2010, 205 (1): 113-126.

[9] Chan T Y, Narasimhan C, Yoon Y. Advertising and price competition in a manufacturer-retailer channel [J]. International Journal of Research in Marketing, 2017: S0167811617300319.

[10] Huang S, Yang C, Zhang X. Pricing and production decisions in dual-channel supply chains with demand disruptions [M]. Pergamum Press, Inc. 2012.

[11] Huang S, Yang C, Liu H. Pricing and production decisions in a dual-channel supply chain when production costs are disrupted [J]. Economic Modelling, 2013, 30 (1): 521-538.
[12] Zheng $\mathrm{H} \mathrm{Z}$, Chu D H, Zhan D C, et al. DUAL SALES CHANNEL MANAGEMENT WITH SERVICE COMPETITION[C]// International Conference on Machine Learning \& Cybernetics. 2008.

[13] Dan B, Xu G, Liu C. Pricing policies in a dual-channel supply chain with retail services [J]. International Journal of Production Economics, 2012, 139 (1): 312---320.

[14] Lu Q, Liu N. Pricing games of mixed conventional and e-commerce distribution channels [J]. Computers \& Industrial Engineering, 2013, 64 (1): 122-132.

[15] Soleimani F, Arshadi Khamseh A, Naderi B. Optimal decisions in a dual-channel supply chain under simultaneous demand and production cost disruptions [J]. Annals of Operations Research, 2014: 1-21. 